\title{
Liver Failure due to Acute Viral Hepatitis (A-E)
}

\author{
Paul Manka a,b,c Jens Verheyen ${ }^{d} \quad$ Guido Gerken $^{a} \quad$ Ali Canbay $^{a}$ \\ a Department of Gastroenterology and Hepatology, University Hospital Essen, Essen, Germany; \\ ${ }^{b}$ Regeneration and Repair Group, The Institute of Hepatology, Foundation for Liver Research, London, UK; \\ ${ }^{\mathrm{c}}$ Division of Transplantation Immunology and Mucosal Biology, King's College, London, UK; \\ dInstitute of Virology, University Hospital, University Duisburg-Essen, Essen, Germany
}

Keywords

Viral hepatitis - Acute liver failure - Hepatitis E virus . Hepatitis $B$ virus reactivation

\section{Summary}

Background: Viral hepatitis is still one of the key causes of acute liver failure (ALF) in the world. Methods: A selective literature search of the PubMed database was conducted, including current studies, reviews, metaanalyses, and guidelines. We obtained an overview of ALF due to viral hepatitis in terms of epidemiology, course, and treatment options. Results: Most fulminant viral courses are reported after infection with hepatitis $A$, $B$, and $B / D$, but not with hepatitis $C$. Hepatitis $E$ is also known to cause ALF but has not gained much attention in recent years. However, more and more autochthonous hepatitis $E$ virus infections have been recently observed in Europe. Reactivation of hepatitis B virus (HBV) under immunosuppressive conditions, such as after intensive chemotherapy, is also an increasing problem. For most viral-induced cases of ALF, liver transplantation represented the only therapeutic option in the past. Today, immediate treatment of HBV-induced ALF with nucleotide or nucleoside analogs is well tolerated and beneficially affects the course of the disease. Conclusion: Although numbers in Western European countries are decreasing rapidly, reliable diagnostic screening for hepatitis $A-E$ is necessary to identify the etiology and to determine those most at risk of developing ALF.

(C) 2016 S. Karger GmbH, Freiburg

\section{Introduction}

Acute liver failure (ALF) is a devastating clinical syndrome associated with high mortality in the absence of immediate state-ofthe-art intensive care, specific treatment, or liver transplantation. It is partly accompanied by the onset of hepatic encephalopathy within 8 weeks of the first symptoms [1]. The American Association for the Study of Liver Disease (AASLD) position paper recommends that all patients with clinical or laboratory evidence of acute hepatitis should have immediate measurement of prothrombin time and careful evaluation for subtle alterations in mentation [2]. The most widely accepted definition proposed by the AASLD includes evidence of coagulopathy (international normalized ratio $\geq$ 1.5) and presence of an altered sensorium (encephalopathy) without pre-existing cirrhosis and with duration of symptoms of less than 26 weeks [3]. For patients meeting this definition, hospital admission, ideally to a transplant center, is mandatory [2].

ALF can occur as a result of various etiologies (overdosing with acetaminophen or other drugs, viral hepatitis, ischemia, and other causes). When ALF is not fatal, the liver has a unique capacity to recover completely, although reliably predicting mortality remains challenging $[4,5]$.

\section{Causes and Epidemiology}

ALF is a rare disease especially in the developed world [3]. The causes of ALF are heterogeneous and may vary from country to country. Traditionally, hepatitis B was regarded as the most common cause of ALF [6]. Over the last decade, statistics suggest a change in ALF etiology in developed countries. According to the United States ALF Group Registry statistics, drug-induced liver injury (DILI), including acetaminophen and idiosyncratic related etiologies, is responsible for more than $50 \%$ of cases, followed by in- 


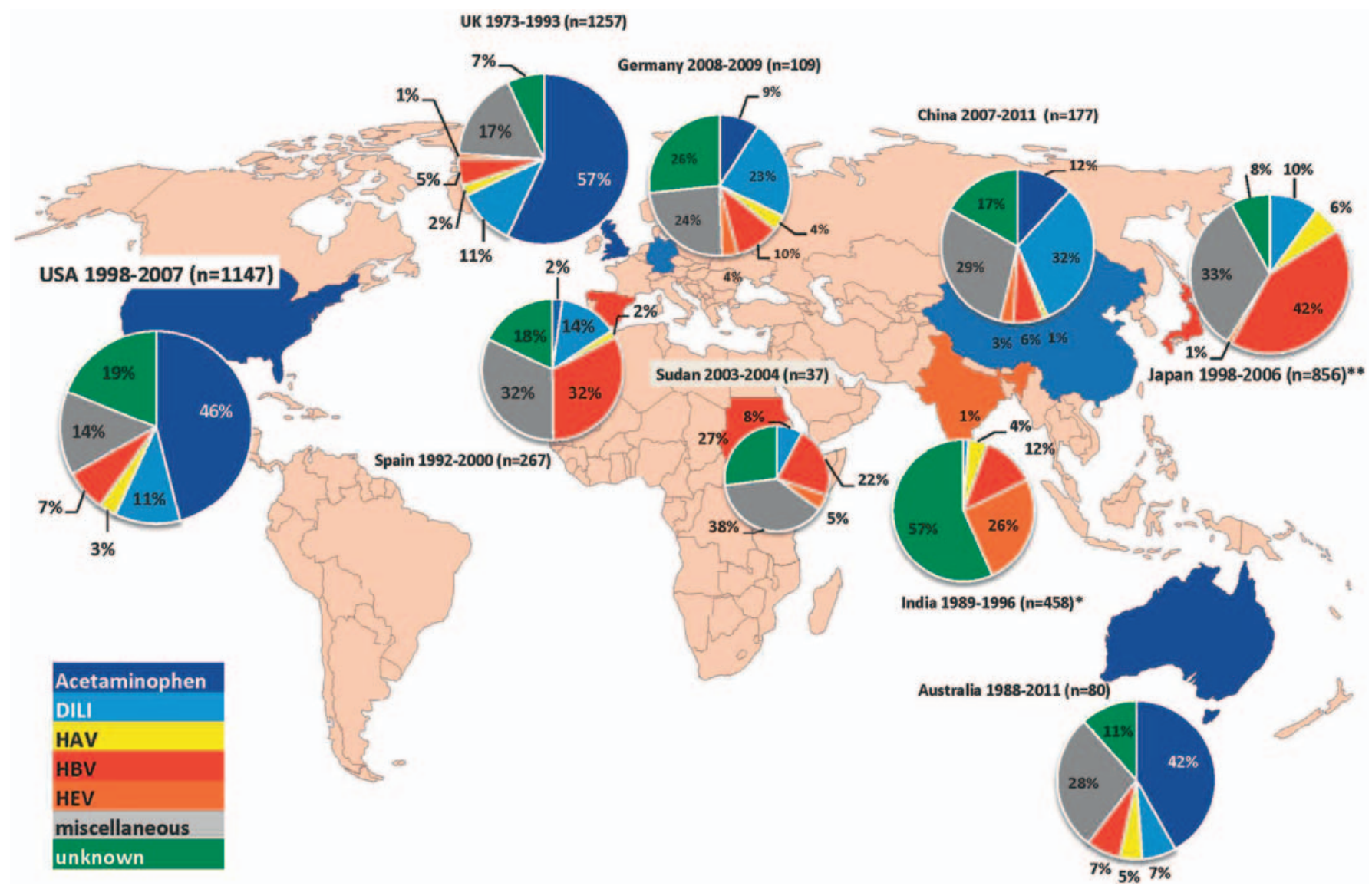

Fig. 1. Causes of ALF worldwide. ${ }^{\star}$ Others include non-A-E viral hepatitis; ${ }^{* *}$ no discrimination between acetaminophen and idiosyncratic drug injury $[3,11,17$, 71-76].

determinate causes (14\%), hepatitis B (7.7\%), and autoimmune hepatitis $(5.9 \%)$, followed by less common causes including ischemia, Wilson's disease, Budd-Chiari syndrome, and pregnancyrelated liver failure (e.g. HELLP syndrome) $[7,8]$. Statistics from Northern European countries and the UK stand in line with statistics from the USA $[3,9]$. Reasons for the decline in viral-related cases of ALF range from successful vaccination programs over improved control of blood products to a more health-educated society [10]. However, statistics from Southern Europe are contrary where viral hepatitis still is a main cause of ALF $[11,12]$. Therefore we can assume a north-south gradient within Europe. Predictions for Eastern Europe will become more sophisticated as statistics with reasonable numbers of patients are reported. As most of those infected with hepatitis B virus (HBV) in the European region live in Eastern European countries [13,14], a severe impact in the role of ALF is likely.

Bernal and Wendon [3] assume that, globally, hepatitis E and A infections are probably responsible for the majority of ALF cases. This can be related to high incidence in some Asian countries. In India, for example, one study reported that $44 \%$ of ALF cases were related to hepatitis E virus (HEV) infection. Similar results were obtained in Bangladesh [15, 16].

In Germany, findings can be categorized alongside recent developments in Europe. Drug toxicity appears to be the major cause of primary ALF. In contrast to findings in the USA and the UK, idiosyncratic drug injuries, rather than acetaminophen, are most commonly related to DILI. Additionally, hepatitis B, with $18 \%$ of all cases, still plays a major role in etiology. The substantial proportion of unknown cases and the fact that the diagnosis of idiosyncratic liver injury is based on the exclusion of other diagnoses leaves the question open whether other etiologies might be overlooked [17]. Indeed, we could prove recently that a reasonable number of patients with ALF might be related to unappreciated hepatitis E infections. Figure 1 provides an overview of the causes of ALF worldwide [18].

\section{Hepatotropic Viruses}

\section{Hepatitis A}

Hepatitis A virus (HAV) can cause liver disease that ranges from mild to severe illness but does not cause chronic liver disease. It is usually transmitted through ingestion of contaminated food and water or through direct contact with infectious persons. Thus, the risk is higher in areas with a lack of safe water and poor sanitation. Transmission by blood transfusion is rare; however, polymerase chain reaction (PCR) testing for blood donors is recommended. Measures to improve these issues as well as vaccination are known 
to be most effective to combat the disease. Usually most patients make a full recovery from hepatitis A [19]. Unfortunately, a small proportion of infected patients develop a fulminant hepatitis with a high mortality rate. The World Health Organization (WHO) calculates that 1.4 million people become infected with HAV each year $[20,21]$.

In Germany, 681 cases of hepatitis A were reported to the Robert Koch Institute (RKI) in 2014. This is the lowest rate since 2001, and the prevalence dropped to $0.8 / 100,000$ inhabitants. Most of the patients acquired their infection within Germany (63\%) [22].

Less than $1 \%$ of acute HAV infections result in ALF [20]. Young children generally belong to the group of patients with unapparent or subclinical hepatitis and have no symptoms or jaundice [23]. In contrast, the infection is more severe in adults, with symptoms occurring in $70 \%$. Generally, hepatitis A-related ALF has a spontaneous survival rate of $69 \%$; the remaining $31 \%$ require emergency liver transplant (ELT) or die [24]. Furthermore, patients with preexisting liver damage such as non-alcoholic fatty liver disease (NAFLD) or alcoholic steatohepatitis (ASH) are more susceptible to develop an acute-on-chronic liver failure in cases of HAV infection [25].

The reasons why HAV infection may progress infrequently to ALF are poorly understood. Underlying host factors such as age and even minor pre-existing liver damage may play a role [26, 27]. Moreover, viral factors including low viral load and a higher rate of substitutions in the 5 untranslated region of the viral genome are also thought to increase the likelihood of a fulminant course [28, 29]. Investigations to find a clear difference in genomic sequences between patients with fulminant courses of HAV and those with a minor course did not lead to clear results [30]. In contrast, there is some evidence that cytolytic T cells may play an important role in the pathogenesis of HAV infection and in determining the course [31]. The declining incidence of HAV infection in developed countries makes it unlikely that great efforts will be taken to target this problem in the near future.

Specific diagnosis can be made by the detection of HAV-specific immunoglobulin (Ig) M and IgG antibodies in serum. Additional tests may include reverse transcription PCR (RT-PCR) to detect the viral RNA. There is currently no specific treatment. With acute hepatitis A, as with many other etiologies of ALF, care is mainly supportive (according to the AASLD guidelines), and if recovery is unlikely, liver transplantation should be considered [2]. Data for outcomes after transplantation is not available.

\section{Hepatitis $B$}

Hepatitis B is a viral infection caused by the HBV and can lead to both acute and chronic liver disease. HBV is a DNA virus and a member of the Hepadnaviridae family that is transmitted through contact with blood or other body fluids of an infected person. In highly endemic areas, hepatitis B is most commonly spread from mother to child at birth (perinatal transmission). In industrialized countries, hepatitis B is mostly spread by sexual transmission. Other modes of transmission include the reuse of needles and syringes either in healthcare settings or among persons who inject
Table 1. Initial laboratory tests to perform in the initial evaluation of ALF (HAV, HBV, HEV) $[2,18]$

\begin{tabular}{ll}
\hline HAV & IgM antibody to HAV (IgM anti-HAV) \\
HBV & hepatitis B surface antigen (HBsAg) \\
& $\begin{array}{l}\text { IgM antibody to hepatitis B core (IgM anti-HBc) } \\
\text { HBV DNA PCR }\end{array}$ \\
HEV & $\begin{array}{l}\text { IgG and IgM antibody to HEV (IgG/IgM anti-HEV) } \\
\text { HEV RNA PCR }\end{array}$ \\
\hline
\end{tabular}

drugs; medical, surgical, and dental procedures; tattooing; and the use of razors and similar objects that are contaminated with infected blood $[32,33]$.

In Germany, the hepatitis B surface antigen (HBsAg) prevalence is less than $1 \%$. In 2014, the RKI reported 755 new infections (0.9 cases per 100,000 inhabitants). A rise in infection rates has been especially observed in metropolitan regions. However, rates in some Asian, African, and Eastern European parts are much higher [22].

In adults, hepatitis B infection is usually asymptomatic. Young children are most likely to develop a chronic infection whereas in adults, less than $5 \%$ of otherwise healthy persons who get infected will develop chronic infection [34]. According to the WHO, one quarter of the world's population (2 billion) is estimated to have experienced HBV infection and 3\% (240 million) are chronically infected with hepatitis B [35]. About $1 \%$ of persons with acute hepatitis develop ALF, which can be regarded as a more atypical course of acute hepatitis [36]. However, in a fulminant course, HBV DNA and HBsAg levels often fall rapidly as liver failure develops; thus, some patients are HBsAg-negative by the time of onset of hepatic coma [37]. Therefore, a transfer to a specialized unit and accurate testing are crucial (table 1). Reasons why some patients develop a fulminant course in comparison to others are not well investigated. Simultaneous intake of alcohol, acetaminophen, or methamphetamines may play a role [38]. In addition, HBV genotype might affect the outcome. In one study comparing the genotypes of chronic HBV patients to cases with HBV-related ALF, the latter showed a higher prevalence of genotype $\mathrm{D}$ [39].

The mechanisms whereby HBV induces ALF are not well known. There are several studies showing that HBV core promoter mutations have been implicated in the pathogenesis of fulminant hepatitis B. A common hallmark of these mutations is a phenotype of enhanced viral replication. It is common in patients with a more aggressive course such as fulminant hepatitis but also in chronic hepatitis. Enhanced viral replication may result in a stronger immune response and extended infection. Consequently, this could be an important factor in driving the disease towards a fulminant course. Moreover, there is also evidence that at least some mutated variants may induce apoptosis in hepatocytes [40, 41]. Furthermore, it is worthwhile mentioning that patients with underlying chronic liver disease are more susceptible to develop acute-onchronic liver failure if infected with certain mutants [42]. However, since patients with fulminant hepatitis exhibit different phenotypes so that a highly replicative phenotype is not exclusive, additional mechanisms must be involved. 
Another possible factor with major impact in HBV-related ALF could be the overwhelming activation of humoral immunity. A massive accumulation of plasma cells secreting IgG and IgM and complement components were found in necrotic areas in livers of HBV-related ALF. Furthermore, these antibodies were found to target hepatitis B core antigen $(\mathrm{HBcAg})[43]$. How relevant these results are for HBV-related ALF and underlying mechanisms needs further investigation, as this particular study has been performed with only 2 patients.

The incidence of reactivation of previously stable subclinical infection with HBV without a manifestation of chronic disease characteristics is steadily rising. This is related to patients with treatment-induced immunosuppression during or after cancer therapy. Therefore, identification of patients at high risk as well as the use of prophylaxis is crucial [44]. High disease activity usually leads to clinical and serological resolution. However, even after serological resolution, small amounts of covalently closed circular DNA (cccDNA) persist in the liver for years, decades, and possibly for the lifetime. T cell immunity suppresses viral replication from these cccDNA copies to very low levels [45]. Mutations in the HBV genome, immunosuppressive therapy, and viral- or drug-induced injury are common causes of reactivation. Fulminant hepatic failure in the setting of HBV reactivation has a much higher morbidity and mortality rate than de novo fulminant hepatitis [46]. The AASLD recommends that patients found to be positive for HBsAg who are to begin such a therapy should be treated prophylactically with a nucleoside analog and that it should be continued for 6 months after completion of immunosuppressive therapy. Moreover, the American Gastroenterological Association recommends in their guidelines to offer $\mathrm{HBsAg}$-negative but anti-HBc-positive patients a prophylactic therapy if treated with B-cell-depleting agents (eg. rituximab) [47].

The prognosis of HBV-related ALF is generally limited without liver transplantation. Transplant-free survival rates range from 26 to $53 \%$ [48]. Hepatitis serological testing should be done for identification of acute viral infection. This should also be performed in case another putative etiology has been identified [2].

To date, there is not enough evidence that artificial liver support devices can enhance the patient's survival. In contrast, there is first evidence that initial antiviral therapy could be beneficial. Jochum et al. [49] could show that immediate treatment of HBV-induced ALF with drugs such as entecavir is well tolerated and beneficially affects the course of the disease. Therefore, the AASLD recommends to take nucleos(t)ide analogs into consideration as a possible treatment option for hepatitis B ALF as well as for the prevention of post-transplant recurrence [2].

\section{Hepatitis $C$}

Although controversial, currently there is no evidence that hepatitis $\mathrm{C}$ alone appears to cause ALF. However, an acute hepatitis $\mathrm{C}$ is able to induce hepatic damage and a severe increase of transaminases. Nevertheless, this does happen without altered synthesis function [50].

\section{Hepatitis D}

Hepatitis D virus (HDV) can be regarded as an altered RNA virus as it is dependent on the coexistence of HBV. The virus consists of only one protein, a circular RNA strand, i.e. the actual hepatitis $\mathrm{D}$ antigen. It requires the $\mathrm{HBs} A g$ for the encapsidation of its own genome. It is further dependent on the sharing of envelope proteins to facilitate the assembly of the HDV genome into new virus particles. Apart from that, the replication of the circular RNA is independent of $\mathrm{HBV}[51,52]$.

In Germany, 17 cases of hepatitis D were reported to the RKI in 2014 [22]. Hepatitis D coinfection may occur in conjunction with acute hepatitis B. In this case, the rate of hepatitis B to progress to ALF approaches 20\%. In addition, HDV superinfection of a chronic HBV patient can also result in ALF [53]. Although there is no specific therapy for hepatitis $\mathrm{D}$ infection, diagnosis is important, as the disease follows a characteristic biphasic pattern in which initial recovery is followed by clinical deterioration.

\section{Hepatitis E}

Approximately $20-40 \%$ of ALF cases are caused by HEV infections in developing countries. However, in western countries, liver failure caused by hepatitis $\mathrm{E}$ has only been recently regarded as an imported infection. In line with this opinion, data from surveys based on population from the USA showed hepatitis $\mathrm{E}$ as a rare cause of ALF [54]. However, recent studies showed HEV seroprevalence rates between 16 and 20\% among adults in industrialized countries [55-57]. Nevertheless, these numbers should be interpreted with caution as results may be influenced by serological assay discrepancies. Despite these inter-assay variations, there is some evidence of autochthonous HEV, particularly genotype 3, being endemic to Europe [58, 59].

In contrast to ALF, a study by Davern et al. [60] from 2013 showed that in a US multicenter study 9 (3\%) patients of 318 cases of suspected DILI were misdiagnosed. After reassessment these cases were considered more likely to be hepatitis E-related [60]. This study is supported by another study, which showed that $22.2 \%$ of patients diagnosed with autochthonous hepatitis $\mathrm{E}$ were initially thought to have DILI prior to HEV testing. Moreover, the investigators could demonstrate that $21.4 \%$ of patients with criterion-referenced DILI had autochthonous hepatitis E after the reassessment of stored serum with HEV testing [61]. These studies underline that a structured assessment of medical history can be difficult. Therefore, it is necessary for western clinicians to take HEV into account as a cause of liver disease when making their treatment assessments.

Indeed, this should also be the case in the setting of ALF. Contrary to results from the USA, one retrospective study from Germany suggests that hepatitis E contributes to a substantial proportion of acute liver injury cases in developed countries [60, 62]. In a retrospective analysis of 80 ALF cases, 8 of these cases have been detected to be potentially hepatitis E-related, suggesting that HEV testing is necessary in every case of ALF. Moreover, this study suggests that it is necessary to perform both serological testing and RNA testing as well [18]. 
In immunocompetent patients, HEV infection usually takes an asymptomatic course [63]. In contrast to descriptions of a higher incidence of chronic hepatitis $\mathrm{E}$ in immunocompromised patients, two case reports of acute hepatitis E claim that steroids may prevent the progress of acute hepatitis E during ALF [64, 65]. Further studies are needed to evaluate whether steroid treatment has a supportive role in hepatitis E-related acute liver injury. However, patients with underlying liver disease as well as the elderly are more likely to show a more dramatic ALF course [62].

There is little known about the impact of acute infections and the likelihood of exacerbation to fulminant liver injury in the setting of immunosuppression and hematopoietic stem cell transplantation (HSCT). Recently, a fatal outcome of autochthonous hepatitis $\mathrm{E}$ in a patient with B-cell lymphoma in France has been reported [66]. However, contrary to HBV, descriptions of fulminant courses in hematological malignancies are rare.
Considering all of the above, the question arises whether antiviral therapies might be effective against HEV-related ALF. There is only little evidence for the use of pegylated interferon alpha and ribavirin to treat chronic HEV infection [67-69]. Ribavirin also seems to be a possible treatment option in acute hepatitis [67]. Descriptions of treatment in ALF are rare although there are occasional reports of successful treatment in acute-on-chronic liver failure [70]. Further trials must be conducted to clarify the need and benefit of any antiviral treatment.

\section{Disclosure Statement}

The authors have nothing to disclose.

\section{References}

1 Trey C, Davidson CS: The management of fulminant hepatic failure. Prog Liver Dis 1970;3:282-298.

2 Polson J, Lee WM; American Association for the Study of Liver Disease: AASLD position paper: the management of acute liver failure. Hepatology 2005;41:11791197

3 Bernal W, Wendon J: Acute liver failure. N Engl J Med 2013;369:2525-2534.

4 Rutherford A, Chung RT: Acute liver failure: mechanisms of hepatocyte injury and regeneration. Semin Liver Dis 2008;28:167-174.

5 Riordan SM, Williams R: Mechanisms of hepatocyte injury, multiorgan failure, and prognostic criteria in acute liver failure. Semin Liver Dis 2003;23:203-215.

6 Canbay A, Tacke F, Hadem J, Trautwein C, Gerken G, Manns MP: Acute liver failure: a life-threatening disease. Dtsch Arztebl Int 2011;108:714-720.

7 Ostapowicz G, Fontana RJ, Schiødt FV, et al: Results of a prospective study of acute liver failure at 17 tertiary care centers in the United States. Ann Intern Med 2002; 137:947-954.

8 Reuben A, Koch DG, Lee WM; Acute Liver Failure Study Group: Drug-induced acute liver failure: results of a U.S. multicenter, prospective study. Hepatology 2010;52:2065-2076.

9 Wei G, Bergquist A, Broomé U, et al: Acute liver failure in Sweden: etiology and outcome. J Intern Med 2007;262:393-401.

10 Daniels D, Grytdal S, Wasley A; Centers for Disease Control and Prevention (CDC): Surveillance for acute viral hepatitis - United States, 2007. MMWR Surveil Summ 2009;58:1-27.

11 Escorsell A, Mas A, de la Mata M; Spanish Group for the Study of Acute Liver Failure: Acute liver failure in Spain: analysis of 267 cases. Liver Transpl 2007;13: 1389-1395.

12 Koskinas J, Deutsch M, Kountouras D, et al: Aetiology and outcome of acute hepatic failure in Greece: experience of two academic hospital centres. Liver Int 2008; 28:821-827.

13 De Franchis R, Hadengue A, Lau G, et al: EASL International Consensus Conference on Hepatitis B. 13-14 September, 2002 Geneva, Switzerland. Consensus statement (long version). J Hepatol 2003;39(suppl 1): S3-25.
4 Ott JJ, Stevens GA, Groeger J, Wiersma ST: Global epidemiology of hepatitis B virus infection: new estimates of age-specific HBsAg seroprevalence and endemicity. Vaccine 2012;30:2212-2219.

15 Khuroo MS, Kamili S: Aetiology and prognostic factors in acute liver failure in India. J Viral Hepat 2003; 10:224-231.

16 Alam S, Azam G, Mustafa G, et al: Natural course of fulminant hepatic failure: the scenario in Bangladesh and the differences from the west. Saudi J Gastroenterol 2009;15:229-233.

17 Hadem J, Tacke F, Bruns T, et al: Etiologies and outcomes of acute liver failure in Germany. Clin Gastroenterol Hepatol 2012;10:664-669.e2.

18 Manka P, Bechmann LP, Coombes JD, et al: Hepatitis $\mathrm{E}$ virus infection as a possible cause of acute liver failure in Europe. Clin Gastroenterol Hepatol 2015;13: 1836-1842; quiz e157-158.

19 Koff RS: Hepatitis A. Lancet 1998;351:1643-1649.

Wasley A, Fiore A, Bell BP: Hepatitis A in the era of vaccination. Epidemiol Rev 2006;28:101-111.

21 Jacobsen KH, Wiersma ST: Hepatitis A virus seroprevalence by age and world region, 1990 and 2005 . Vaccine 2010;28:6653-6657.

22 Robert Koch-Institut: Infektionsepidemiologisches Jahrbuch meldepflichtiger Krankheiten für 2014. 2015. www.rki.de/DE/Content/Infekt/Jahrbuch/Jahrbuch_2014.pdf?_blob=publicationFile.

23 Romero R, Lavine JE: Viral hepatitis in children. Semin Liver Dis 1994;14:289-302.

24 Taylor RM, Davern T, Munoz S, et al: Fulminant hepatitis A virus infection in the United States: incidence, prognosis, and outcomes. Hepatology 2006;44:15891597.

25 Canbay A, Chen S-Y, Gieseler RK, et al: Overweight patients are more susceptible for acute liver failure. Hepatogastroenterology 2005;52:1516-1520.

26 Brown GR, Persley K: Hepatitis A epidemic in the elderly. South Med J 2002;95:826-833.

27 Vento S: Fulminant hepatitis associated with hepatitis A virus superinfection in patients with chronic hepatitis C. J Viral Hepat 2000;7(suppl 1):7-8.
28 Fujiwara K, Yokosuka O, Ehata T, et al: Association between severity of type A hepatitis and nucleotide variations in the 5 ' non-translated region of hepatitis A virus RNA: strains from fulminant hepatitis have fewer nucleotide substitutions. Gut 2002;51:82-88.

29 Rezende G, Roque-Afonso AM, Samuel D, et al: Viral and clinical factors associated with the fulminant course of hepatitis A infection. Hepatology 2003;38: 613-618.

30 Ajmera V, Xia G, Vaughan G, et al: What factors determine the severity of hepatitis A-related acute liver failure? J Viral Hepat 2011;18:e167-174.

31 Vallbracht A, Gabriel P, Maier K, et al: Cell-mediated cytotoxicity in hepatitis A virus infection. Hepatology 1986;6:1308-1314.

32 Dienstag JL: Hepatitis B virus infection. N Engl J Med 2008;359:1486-1500.

33 Trépo C, Chan HLY, Lok A: Hepatitis B virus infection. Lancet 2014;384:2053-2063.

34 Torbenson M, Thomas DL: Occult hepatitis B. Lancet Infect Dis 2002;2:479-486.

35 Guidelines for the Prevention, Care and Treatment of Persons with Chronic Hepatitis B Infection. Geneva, World Health Organization, 2015. www.ncbi.nlm.nih. gov/books/NBK305553/ (accessed on November 22, 2015).

36 Lavanchy D: Hepatitis B virus epidemiology, disease burden, treatment, and current and emerging prevention and control measures. J Viral Hepat 2004;11:97107

37 Liang TJ: Hepatitis B: The virus and disease. Hepatology 2009;49:S13-S21.

38 Jindal A, Kumar M, Sarin SK: Management of acute hepatitis B and reactivation of hepatitis B. Liver Int 2013;33(suppl 1):164-175.

39 Garfein RS, Bower WA, Loney CM, et al: Factors associated with fulminant liver failure during an outbreak among injection drug users with acute hepatitis $\mathrm{B}$. Hepatology 2004;40:865-873.

40 Baumert TF, Yang C, Schürmann P, et al: Hepatitis B virus mutations associated with fulminant hepatitis induce apoptosis in primary Tupaia hepatocytes. Hepatology 2005;41:247-256. 
41 Bechmann LP, Jochum C, Kocabayoglu P, et al: Cytokeratin 18-based modification of the MELD score improves prediction of spontaneous survival after acute liver injury. J Hepatol 2010;53:639-647.

42 Xiao L, Zhou B, Gao H, et al: Hepatitis B virus genotype B with G1896A and A1762T/G1764A mutations is associated with hepatitis B related acute-on-chronic liver failure. J Med Virol 2011;83:1544-1550.

43 Farci P, Diaz G, Chen Z, et al: B cell gene signature with massive intrahepatic production of antibodies to hepatitis B core antigen in hepatitis B virus-associated acute liver failure. Proc Natl Acad Sci U S A 2010;107: 8766-8771.

44 Hoofnagle JH: Reactivation of hepatitis B. Hepatology 2009;49:S156-165.

45 Rehermann B, Ferrari C, Pasquinelli C, Chisari FV: The hepatitis B virus persists for decades after patients' recovery from acute viral hepatitis despite active maintenance of a cytotoxic T-lymphocyte response. Nat Med 1996;2:1104-1108.

46 Mindikoglu AL, Regev A, Schiff ER: Hepatitis B virus reactivation after cytotoxic chemotherapy: the disease and its prevention. Clin Gastroenterol Hepatol 2006;4: 1076-1081.

47 Reddy KR, Beavers KL, Hammond SP, Lim JK, FalckYtter YT: American Gastroenterological Association Institute guideline on the prevention and treatment of hepatitis B virus reactivation during immunosuppressive drug therapy. Gastroenterology 2015;148:215-219.

48 Lee HC: Acute liver failure related to hepatitis B virus. Hepatol Res 2008;38(suppl 1):S9-S13.

49 Jochum C, Gieseler RK, Gawlista I, et al: Hepatitis Bassociated acute liver failure: immediate treatment with entecavir inhibits hepatitis B virus replication and potentially its sequelae. Digestion 2009;80:235-240.

50 Maheshwari A, Ray S, Thuluvath PJ: Acute hepatitis C. Lancet 2008;372:321-332.

51 World Health Organization. WHO|Hepatitis D. www who.int/csr/disease/hepatitis/whocdscsrncs20011/en/ (accessed on November 23, 2015).
Taylor JM: Hepatitis delta virus. Virology 2006;344: 71-76.

53 Shukla NB, Poles MA: Hepatitis B virus infection: coinfection with hepatitis $C$ virus, hepatitis $D$ virus, and human immunodeficiency virus. Clin Liver Dis 2004;8: 445-460, viii.

54 Fontana RJ, Engle RE, Trivedi S, et al: The role of hepatitis $\mathrm{E}$ virus infection in adult American patients with acute liver failure. Hepatology 2012;56:958A-959A.

55 Kuniholm MH, Purcell RH, McQuillan GM, Engle RE, Wasley A, Nelson KE: Epidemiology of hepatitis E virus in the United States: results from the Third National Health and Nutrition Examination Survey, 1988-1994. J Infect Dis 2009;200:48-56.

56 Faber MS, Wenzel JJ, Jilg W, Thamm M, Höhle M, Stark K: Hepatitis E virus seroprevalence among adults, Germany. Emerging Infect Dis 2012;18:16541657.

57 Pavio N, Mansuy J-M: Hepatitis E in high-income countries. Curr Opin Infect Dis 2010;23:521-527.

58 Dalton HR, Bendall R, Ijaz S, Banks M: Hepatitis E: an emerging infection in developed countries. Lancet Infect Dis 2008;8:698-709.

59 Lewis HC, Wichmann O, Duizer E: Transmission routes and risk factors for autochthonous hepatitis $\mathrm{E}$ virus infection in Europe: a systematic review. Epidemiol Infect 2010;138:145-166

60 Davern TJ, Chalasani N, Fontana RJ, et al: Acute hepatitis $\mathrm{E}$ infection accounts for some cases of suspected drug-induced liver injury. Gastroenterology 2011;141: 1665-1672.e1-9.

61 Dalton HR, Fellows HJ, Stableforth W, et al: The role of hepatitis E virus testing in drug-induced liver injury. Aliment Pharmacol Ther 2007;26:1429-1435.

62 Crossan CL, Simpson KJ, Craig DG, et al: Hepatitis E virus in patients with acute severe liver injury. World J Hepatol 2014;6:426-434.

63 Stoszek SK, Engle RE, Abdel-Hamid M, et al: Hepatitis E antibody seroconversion without disease in highly endemic rural Egyptian communities. Trans R Soc Trop Med Hyg 2006;100:89-94.
64 Vieira CL, Baldaia C, Fatela N, Ramalho F, Cardoso C: Case of acute hepatitis $\mathrm{E}$ with concomitant signs of autoimmunity. World J Hepatol 2013;5:152-155.

65 Sebode M, Pischke S, Lütgehetmann M, et al: New foe treated with old guns - supportive role of steroids in the treatment of acute severe hepatitis E. BMC Gastroenterology 2014;14:191.

66 Doudier B, Vencatassin H, Aherfi S, Colson P: Fatal fulminant hepatitis $\mathrm{E}$ associated with autoimmune hepatitis and excessive paracetamol intake in Southeastern France. J Clin Microbiol 2014;52:1294-1297.

67 Pischke S, Hardtke S, Bode U, et al: Ribavirin treatment of acute and chronic hepatitis E: a single-centre experience. Liver Int 2013;33:722-726.

68 Alric L, Bonnet D, Laurent G, Kamar N, Izopet J: Chronic hepatitis E virus infection: successful virologic response to pegylated interferon-alpha therapy. Ann Intern Med 2010;153:135-136.

69 Kamar N, Izopet J, Tripon S, et al: Ribavirin for chronic hepatitis $\mathrm{E}$ virus infection in transplant recipients. N Engl J Med 2014;370:1111-1120.

70 Goyal R, Kumar A, Panda SK, Paul SB, Acharya SK: Ribavirin therapy for hepatitis $\mathrm{E}$ virus-induced acute on chronic liver failure: a preliminary report. Antivir Ther (Lond) 2012;17:1091-1096.

71 Lee WM, Squires RH, Nyberg SL, Doo E, Hoofnagle $\mathrm{JH}$ : Acute liver failure: summary of a workshop. Hepatology 2008;47:1401-1415.

72 Acharya SK, Panda SK, Saxena A, Gupta SD: Acute hepatic failure in India: a perspective from the East. J Gastroenterol Hepatol 2000;15:473-479.

73 Zhao P, Wang C, Liu W, et al: Causes and outcomes of acute liver failure in China. PLoS One 2013;8:e80991.

74 Mudawi HM: Epidemiology of viral hepatitis in Sudan. Clin Exp Gastroenterol 2008;1:9-13.

75 Oketani M, Ido A, Tsubouchi H: Changing etiologies and outcomes of acute liver failure: a perspective from Japan. J Gastroenterol Hepatol 2011;26(suppl 1):65-71.

76 Gow PJ, Jones RM, Dobson JL, Angus PW: Etiology and outcome of fulminant hepatic failure managed at an Australian liver transplant unit. J Gastroenterol Hepatol 2004;19:154-159. 